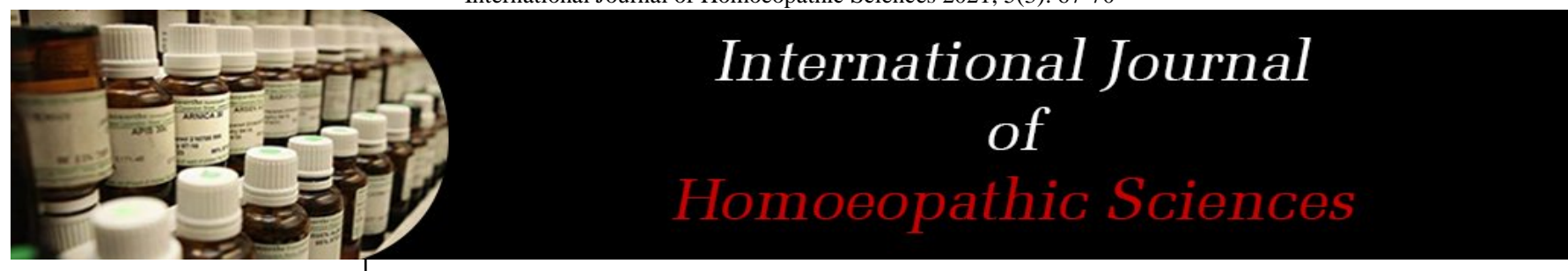

E-ISSN: 2616-4493 P-ISSN: 2616-4485 www.homoeopathicjournal.com IJHS 2021; 5(3): 67-70

Received: 05-03-202

Accepted: 30-04-2021

Dr. Vandana Shukla BHMS Gold Medallist, MD (HOM) Sri Sai Nath Post Graduate Institute of Homoeopathy, Allahabad, Uttar Pradesh, India
Corresponding Author: Dr. Vandana Shukla BHMS Gold Medallist, MD (HOM) Sri Sai Nath Post Graduate Institute of Homoeopathy, Allahabad, Uttar Pradesh, India

\title{
Homoeopathic treatment of nodular goitre: A Case report
}

\section{Dr. Vandana Shukla}

DOI: https://doi.org/10.33545/26164485.2021.v5.i3b.404

\section{Abstract}

The normal thyroid gland is a fairly homogenous structure, but nodules often form within its substance. These nodules may be only the growth and fusion of localized colloid-filled follicles, or more or less discrete adenomas, or cysts. Benign nodular goitre is one of the most common endocrine disorders, especially in countries where iodine deficiency is endemic ${ }^{[1]}$. Management of thyroid nodules depends upon an assessment of thyroid function, fine needle aspiration cytology and imaging. Nodular goitre presents rarely before middle age and maximum found in females than in males ${ }^{[2]}$. Adenomatous or colloid multinodular goitre (MNG) are common, occurring in three to five percent of the general population, haemorrhage, fibrosis and calcification is found within goiters. Though a few cases records can be seen in past where the success gain by homoeopathic medicines, but proper assessment does not define the case was presented here which is treated by homoeopathic medicine Lycopodium over a period of 6 months with steady improvement.

Keywords: Homoeopathy, nodular goitre, colloid goitre, lycopodium.

\section{Introduction}

Nodular goitre is common in the area where there is low iodine concentration in the diet and drinking water; it is also known as endemic goitre. Due to low iodine intake, T3\&T4 production decreases and because of low amount of thyroid hormone, TSH increases. TSH further stimulate thyroid follicles so hyperplasia occurs in thyroid cells. Two types of changes can be seen. Due to accumulation of colloid, follicles develop into colloid goitre (According to Marine's observation ${ }^{[4]}$, it has been commonly accepted that colloid goiters perpetually result from colloid repletion of initial hyperplastic goiters after cessation of the goitrogenic stimulus). And some develop into nodular types and this nodular goitre develops compression symptoms.

Compression of the trachea may leads to breathing troubles. Compression of the oesophagus may leads to dysphagia. Dizziness also be seen when the arms are raised above the head. In some patients, hyperthyroidism may develop which is known as toxic nodular goitre. Thyroid nodules are common entities, frequently discovered in clinical practice, either during physical examination, but also incidentally, during various imaging procedures. Serum thyrotropin (TSH) and thyroid ultrasonography (US) are `pivotal in the evaluation of thyroid nodules, as they provide important information regarding thyroid nodule functionality and the presence of features suspicious for malignancy, respectively. Fine needle aspiration (FNA) biopsy is the most accurate and reliable tool for diagnosing thyroid malignancy and selecting candidates for surgery. Thyroid nodules are 4 times more common in women than men and their frequency increases with age and low iodine intake ${ }^{[3]}$. Thyroid nodules are clinically important for several reasons. They may cause thyroid dysfunction and, rarely, compressive symptoms, but they are primarily important because of the need to exclude thyroid cancer. Ultrasonography plays an essential role in the evaluation of thyroid nodules, and elastography may prove to be a valuable addition. Other imaging studies, including MRI, CT, and 18FDG-PET scans may be helpful in certain circumstances. Thyroid function test (TFT), Fine Needle Aspiration Cytology (FNAC) and Computerised Tomography (CT) were advised. Although TFT was normal, All other haematological and biochemical profile were within the normal range. On the basis above findings, the patient was planned for surgery. 


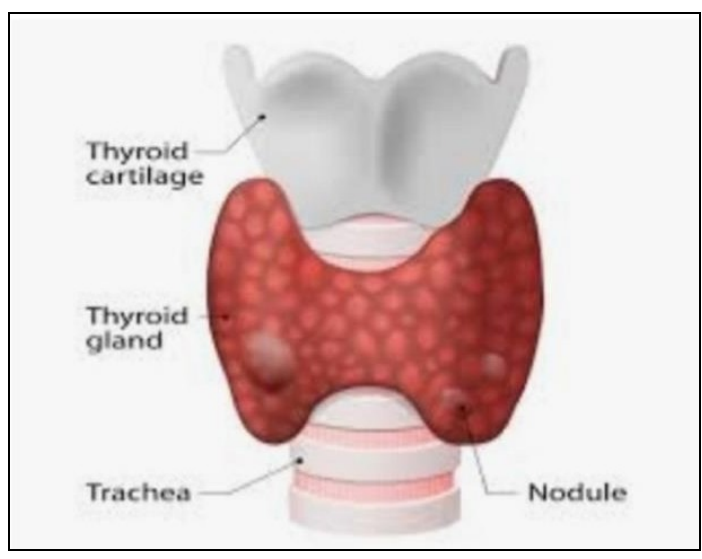

Fig 1: Thyroid Nodules

\section{Incidence}

They tend to occur in certain geographical areas with iodine-depleted soil, usually areas away from the sea coast. Small to moderate-sized goitres are relatively common in the United States. And Intermountain regions, Midwest the Great Lakes, Midwest, and were once known as the "goitre belt." The routine use of iodized table salt now helps prevent this deficiency.

\section{Risk Factors}

Female, age more than 40, having an inadequate dietary intake of iodine, living in an endemic area, and history of goitres also run in the family.

\section{Investigations}

- Thyroid scan: (CT and MRI)

- Thyroid ultrasonography. The least invasive test is a thyroid ultrasound. It will identify other cervical masses that can be confused with a thyroid nodule, such as a thyroglossal dust cyst, and determine whether the nodule is cystic, solid or mixed)

- Blood tests, thyroid function test including thyroid stimulating hormone (TSH, T3, and T4).

- Urinary examination for iodine.

\section{Treatment}

There are a lot of homoeopathic medicines of which a similimum can help a patient for keeping the diseases for a way for a more drawn out period as given in this case Generally in allopathic treatment, Thyroid hormone replacement therapy is prescribed for iodine deficiency. If the goitre is producing too much thyroid hormone, treatment with antithyroid medication or surgery may be necessary. A large goitre which restricts swallowing and breathing may require partial or complete removal of the thyroid gland. But our homoeopathic treatment is safe and gentle and treats the patient in a financially savvy way. Homoeopathic the treatment has no side effects and holistically it treats the individuals.

\section{Prognosis}

The prognosis is good with treatment. An insistent goitre may become toxic. Sudden enlargement of a thyroid gland may indicate internal bleeding or immune disorder and requires immediate medical attention.

\section{Complication}

If there is a single, dominant nodule or if a nodule is enlarged, it may lead to thyroid malignancy (cancer), a fine needle biopsy should be performed to exclude malignancy. A simple goitre may progress to a toxic nodular goitre.

\section{Prevention}

Use iodized salt, or foods supplemented with iodine.

\section{Data collection}

The case was selected from OPD of XXX. Homoeopathic medical college and hospital.

\section{Case Report}

Name of the patient: $\mathrm{Xxxx}$

Age Sex: 39/ Female

Habitat / Address: Kannauj Occupation: - Housewife

Complain Started from 2.5 month with high fever

Duration: from: 2.5 month

Location: Hard Nodule $=$ colloid goitre $8.2 * 3.6 \mathrm{~mm}$ are seen in right lobe.

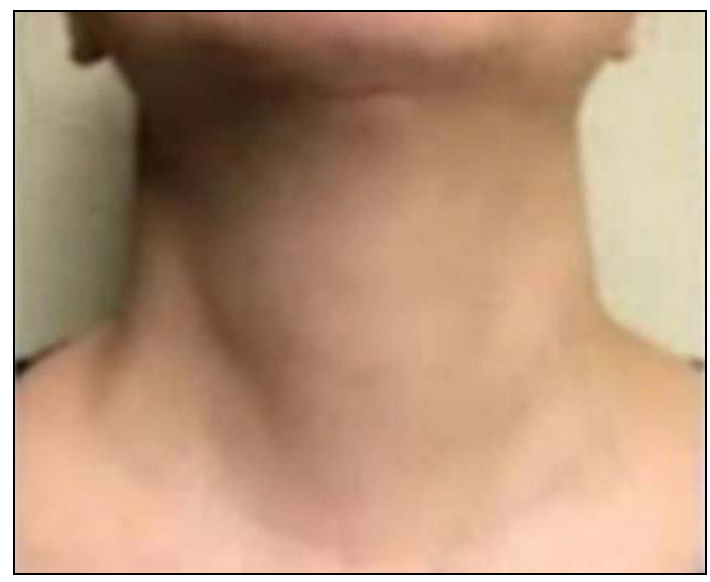

Fig 2: Before Treatment

In left lobe: $30.3 * 24.5 \mathrm{~mm}$ is seen, while touching it seems hot.

- Soreness present in throat and hoarseness especially in morning.

- Left neck: Inflammation seen.

- Pain also in vertex: Pulsating.

- Patient also complain of pain in chest on talking

- Deafness present in right ear

- Tongue appearance: Yellow coated tongue

- Pain in waist: Which relief when patient urinate?

- Complaints aggravated from flatulent food and evening time.

- Food and drink come out through the nose on swallowing.

- Urinary complaints: Frequent Micturition-ProfuseIncontinence.

- Tingling Sensation: In heels.

- Rectum: Constipated; when straining then ineffectual urging. When she goes anywhere. Pain from cold drinks.

\section{Past History}

- History of renal stone: Operated two years ago

- Residual renal impairment

Family History

- Husband: Mentally Disturb. 
- Father: Cancer

- Mother: Kidney failure

- Sister: Bone T.B

- Brother: Normal Homoeopathic Generals Physical General

- Appetite: Increased.

- Thirst: Normal.

- Desire: Sweet things.

- Aversion: Flatulent food aggravation.

- Perspiration: Profuse

- Sleep: Normal (Un-refreshing sleep), waking from fright.

- Dreams: Religious.

- Relation with Hot and cold: Hot Patient

\section{Mental General}

- Patient having weakness of memory and confusion and spell wrongly.

- Desire for company present in patient.

- Great despair found in patient with lack of selfconfidence.

- Patient was trying to hide her feeling.

- Fear of people (especially unknown person)

- Fear of responsibility.
- $\quad$ Frowning of the eyebrow seen.

Systemic Eyes: Myopic

Ear: Deafness in the right ear

Extremities: Normal

Abdomen: Epigastrium region- painful.

Repertorization Totality ${ }^{[6,7,8]}$

- Mind- Fear-People of

- Mind-Confidence- Want of Self-confidence.

- Mind-Company-Desire for.

- Mind-Despair

- Mind: Memory-weakness of memory

- Head: Pain-vertex

- Hearing: Impaired

- Throat: Inflammation

- External Throat: Goitre

- Neck: Swelling-external

- Stomach: Appetite-Ravenous

- Abdomen: Flatulance

- Rectum: Constipation-Ineffectual urging and straining

- Bladder: Urination- involuntary

- Extremities: Tingling- lower limbs

Table 1: Medicine Prescribed \& Follow up

\begin{tabular}{|l|c|c|c|}
\hline & Date & Medicine Prescribed & Improvement \\
\cline { 2 - 4 } & 15-Feb-19 & Lyco 200 Single Dose, Placebo 30,TDS & Soreness in the throat improved, Hoarseness relief \\
\hline Follow up & 01-Mar-19 & Lyco 200 Single Dose, Placebo 30,TDS & Inflammation in the throat decreases \\
\hline Follow up & 15-Mar-19 & Placebo 30, TDS & Better feeling in the abdomen \\
\hline Follow up & 29-Mar-19 & Lyco 200 Single Dose & Constipation relief with better urinary trouble \\
\hline Follow up & 12-Apr-19 & Placebo 30, TDS & Swelling in the throat decreases continuously \\
\hline Follow up & 26-Apr-19 & Placebo 30, TDS & Memory improved with relief in headache. \\
\hline Follow up 10-May-19 & Lyco 200 Single Dose & Tingling sensation in lower limb Subside \\
\hline Follow up $24-M a y-19$ & Placebo 30, TDS & Nodular Gotire is improved. On further follow up no complains, no lesion seen \\
\hline Follow up & 07-Jun-19 & Placebo 30, TDS & .
\end{tabular}

\section{Discussion and conclusion}

After analysis and evaluation of characteristic symptoms totality of symptoms are obtained. Selection of remedy based on the repertorisation of the case. Repertory used here is synthesis repertory. On the basis of reportorial analysis (lycopodium has scored the highest marks among other remedies.it covering most of the rubrics.) and consulting it with Materia medica by using organon of medicine principle I prescribed here lycopodium 200 in single dose followed by placebo fpr 15 days on the first visit.
Remedy selection and follow up of the case: Lycopodium prescribed in 200 potency in a single dose followed by placebo for 15 days on the first visit. After

15 days the second dose of lycopodium was given in second visit. Thereafter patient has been on placebo with continuous steady improvement. The improvement of the patient confirms the principle of single medicines, minimum dose and infrequent repetition as suggested by our master Hahnemann ${ }^{[5]}$. This is the case, which speaks about the success of homoeopathy in the management of goitre.

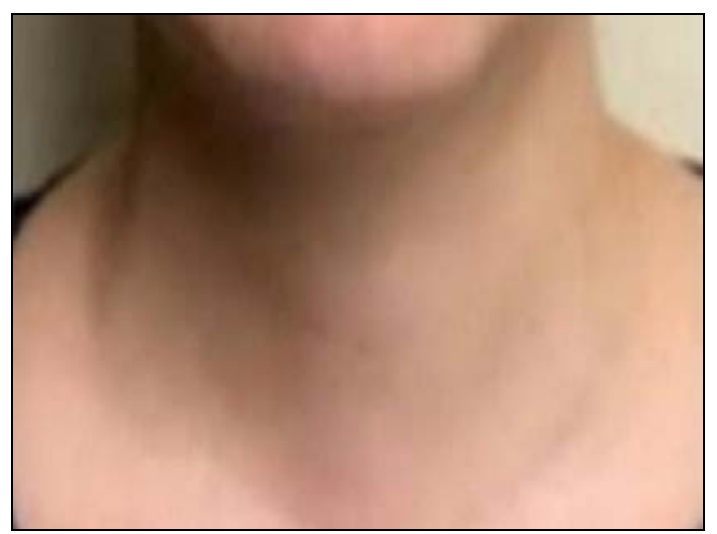

Fig 3: After Treatment 


\section{Investigation}

Neck Ultrasound (4-june-2019): No evidence of nodules on both sides of thyroid lobes.

\section{References}

1. Matovinovic J. Endemic goiter and cretinism at the dawn of the third millennium. Annual review of nutrition 1983;3(1):341-412.

2. Sharma B. A case of colloidal nodular goiter 2011.

3. Mazzaferri EL. Management of a solitary thyroid nodule. New England Journal of Medicine 1993;328(8):553-559.

4. Marine D. Certain Features of the Morphologic Pathology of Endemic Goiter 1928, 68- 82.

5. Hahnemann S. Organon of medicine, 5th. and 6th. Edition. New Delhi, B. Radar 10: Schroyens F.,Synthesis 9.0 (English) by F Schroyens 1995.

6. Kent JT. Lectures on homoeopathic philosophy. B. Jain publishers 2003, 766-72.

7. Adi BS. Effective of Hydrastis in Treatment of Cholelithiasis-An Observation Study. International Journal for Advance Research and Development. 2017;2(10):65-9.

8. Clarke JH. A dictionary of practical materia medica. New Delhi: B 1999, 549-62.

9. Pang HN, Chen CM. Incidence of cancer in nodular goitres. Annals-Academy of Medicine Singapore 2007;36(4):241.

10. Boukis MA, Koutras DA, Souvatzoglou A, Evangelopoulou A, Vrontakis M, Moulopoulos SD. Thyroid hormone and immunological studies in endemic goiter. The Journal of Clinical Endocrinolog \& Metabolism 1983;57(4):859-862.

11. Zhao J, Wang P, Shang L, Sullivan KM, Van Der Haar F, Maberly G. Endemic goiter associated with high iodine intake. American journal of public health 2000;90(10):1633.

12. Gaitan E, Nelson NC, Poole GV. Endemic goiter and endemic thyroid disorders. World journal of surgery 1991;15(2):205-215.

13. Yeung MJ, Serpell JW. Management of the solitary thyroid nodule. The oncologist 2008;13(2):105-112.

14. Bennedbæk FN, Perrild H, Hegedüs L. Diagnosis and treatment of the solitary thyroid nodule. Results of a European survey. Clinica endocrinology 1999;50(3):357-363.

15. Tan GH, Gharib H, Reading CC. Solitary thyroid nodule: comparison between palpation and ultrasonography. Archives of internal Medicine 1995;155(22):2418-2423.

16. Hegedüs L. The thyroid nodule. New England Journal of Medicine 2004;351(17):1764-1771.

17. Van Herle AJ, Rich P, Ljung BME, Ashcraft MW, Solomon DH, Keeler EB. The thyroid nodule. Annals of Internal Medicine 1982;96(2):221-232.

18. Bomeli SR, LeBeau SO, Ferris RL. Evaluation of a thyroid nodule. Otolaryngologic clinics of North America 2010;43(2):L229-238. 